\title{
Dietary Patterns and Hearing Loss in Older People
}

\author{
N.E. Gallagher ${ }^{1}$, C.E. Neville ${ }^{1}$, N. Lyner ${ }^{1}$, J. Yarnell ${ }^{1}$, J.E. Gallacher ${ }^{2}$, Y. Ben-Shlomo ${ }^{3}$, \\ A. Fehily ${ }^{4}$ and J.V. Woodside ${ }^{1}$ \\ ${ }^{1}$ Centre for Public Health, Queen's University, Belfast, BT12 6BJ, UK, ${ }^{2}$ Department of Psychiatry, \\ Universityof Oxford, OX3 7JX, UK, ${ }^{3}$ School of Social and Community Medicine, University of Bristol, Canynge Hall, \\ Bristol, BS8 2 PS UK and ${ }^{4} M R C$ Epidemiology Unit, Cardiff, CF2 3AS, UK
}

Hearing loss is highly prevalent in older people and can reduce quality of life substantially. Emerging research suggests that potentially modifiable risk factors, including risk factors previously related to cardiovascular disease risk ${ }^{(1,2)}$, may be associated with a decreased or increased risk of hearing loss. This has prompted investigation into the possibility that certain nutrients, foods or dietary patterns may also be associated with incidence of hearing loss. We prospectively investigated the association between dietary patterns and hearing loss in men enrolled in the Caerphilly study.

The Caerphilly study began in 1979-1983 with recruitment of 2512 men aged 45-59 years. Dietary data was collected using a selfadministered, semi-quantitative, 56-item food-frequency questionnaire at baseline (first phase; 1979-1983) and pure-tone unaided audiometric threshold was assessed at $0 \cdot 5,1,2$ and $4 \mathrm{kHz}$ during phase two $(1984-1988)^{(3)}$. Factor (principal component) analysis was carried out to determine a posteriori dietary patterns and multivariate linear regression models were used to examine associations with hearing loss (assessed as pure tone average, $\mathrm{dB}$ ).

Three dietary patterns were determined using factor analysis- Traditional, Healthy, High sugar/Alcohol avoider. Unadjusted univariate analysis showed a significant and inverse association between the Healthy pattern and hearing loss $(\beta=-1 \cdot 24 ; 95 \%$ $\mathrm{CI}=-1 \cdot 60,-0.88 ; \mathrm{P}$ value $<0.001)$ and a significant association between the High sugar/Alcohol avoider pattern and hearing loss $(\beta=0.82 ; 95 \% \mathrm{CI}=0.45,1.18 ; \mathrm{P}$ value $<0.001)$. Moreover, once the regression model was adjusted for potential confounding factors, the inverse association between the Healthy pattern and hearing loss remained significant $(\mathrm{P}=0.001)$ as shown in the table below.

\begin{tabular}{|c|c|c|}
\hline \multicolumn{3}{|l|}{ Dietary pattern } \\
\hline $\begin{array}{l}\text { Traditional } \\
\text { Mean difference }(95 \% \mathrm{CI})\end{array}$ & Healthy & $\begin{array}{l}\text { High sugar/Alcohol avoider } \\
\text { Mean difference }(95 \% \mathrm{CI})\end{array}$ \\
\hline Mean difference $(95 \% \mathrm{CI})$ & Mean difference $(95 \% \mathrm{CI})$ & Mean difference $(95 \% \mathrm{CI})$ \\
\hline $\begin{array}{l}\text { ref } \\
-0 \cdot 24(-1.89,1.41) \\
0.20(-1.42,1.82) \\
-0 \cdot 23(-1.88,1.42) \\
0.86(-0.84,2.55)\end{array}$ & $\begin{array}{l}\text { ref } \\
0.23(-1.47,1.93) \\
-1.04(-2.73,0.64) \\
-1.28(-2.98,0.42) \\
-2.66(-4.41,0.91)\end{array}$ & $\begin{array}{l}\text { ref } \\
-1 \cdot 15(-2 \cdot 77,0 \cdot 47) \\
0 \cdot 21(-1 \cdot 41,1 \cdot 83) \\
1.56(-0 \cdot 10,3 \cdot 22) \\
0.31(-1 \cdot 44,2 \cdot 06)\end{array}$ \\
\hline $0 \cdot 37$ & 0.001 & 0.07 \\
\hline
\end{tabular}

model*

0.37

0.001

* Adjusted for age, height, weight, body mass index, systolic blood pressure, smoking, alcohol consumption, physical activity level score, social class, occupation, diabetes, high density lipoprotein cholesterol and total cholesterol; $C I$, confidence interval; $Q$, quintile of factor scores of dietary patterns; ref, reference group.

A healthy dietary pattern was found to be significantly inversely associated with hearing loss in middle aged men in the Caerphilly study. The role of dietary factors in hearing loss remains to be fully established and warrants further investigation.

1. Gopinath B, Flood VM, Rochtchina E et al. (2010) Am J Clin Nutr 92, 416-421.

2. Torre P, Cruickshanks KJ, Klein BEK et al. (2005). J Speech Lang Hear Res 48, 471-481.

3. Gallacher J, Ilubaera V, Ben-Shlomo Y et al. (2012) Neurology 79, 1583-1590. 